\title{
CRÍTICA TEATRAL EN EL ARTISTA: DEFENSA DEL NUEVO DRAMA ROMÁNTICO
}

\author{
Nadia Rebeca VAÍlLO GARRI \\ nadia.vaillo@ua.es \\ Universidad de Alicante
}

\begin{abstract}
Resumen
El Artista, revista literaria del primer tercio del siglo XIX, establece como principal objetivo la defensa de la nueva escuela romántica; propósito este que se muestra de modo evidente en los artículos de crítica literaria. Las reseñas sobre teatro no solo analizan y valoran las propias representaciones, sino que además reflexionan sobre los principios y polémicas del nuevo movimiento. Concretamente, los editores de esta revista madrileña denuncian el lamentable estado en el que se halla el teatro, fruto del escaso afecto e interés que el público le prodiga a las bellas artes españolas. Asimismo, critican los errores estéticos y estilísticos de la vieja y obsoleta escuela neoclásica. La difusión del nuevo drama romántico también tiene cabida en estas páginas destinadas al análisis literario, donde los colaboradores de El Artista defienden con vehemencia estas piezas teatrales, convertidas en objeto de crítica por parte de algunos sectores.
\end{abstract}

Palabras clave: El Artista, romanticismo, crítica teatral, decadencia del teatro, nuevo drama romántico.

\begin{abstract}
El Artista, a literary journal from the first third of the 19th century, establishes the defence of the new romantic school as its main goal; such purpose is very noticeable in the articles devoted to literary criticism. The theatre reviews not only analyse and evaluate the performances themselves, but also reflect on the new movement's principles and controversial aspects. Specifically, this Madrid-based magazine's editors denounce the regrettable conditions for theatre, due to how little affect or interest Spanish fine arts receive form the public. Likewise, they criticise the aesthetic and stylistic flaws in the outdated neoclassical school. The dissemination of new romantic drama finds its space as well within these pages aimed at literary analysis; there, El Artista's
\end{abstract}

Anales, 25, 2013, pp. 383-395 
collaborators vehemently advocate for these theatrical pieces, which had become an object of criticism for some.

Keywords: El Artista, Romanticism, theatre criticism, decadence of theatre, new romantic drama.

El Artista, cuyo primer número vio la luz el domingo 4 de enero de 1835, surgió con el evidente propósito de divulgar y defender el incipiente movimiento romántico ${ }^{1}$. Sus editores, Eugenio de Ochoa y Federico de Madrazo, expresaron la esencia de esta corriente literaria en distintos artículos de carácter polémico e introdujeron composiciones poéticas y narrativas de marcado gusto romántico. Pero si algún género asumió de forma especial la defensa de la nueva escuela, este fue el teatral. Por ello, existen numerosos artículos que, desde diferentes perspectivas, abordan el teatro del siglo XIX, ya sea para debatir sobre las polémicas del momento, para reseñar una obra concreta o para comentar la actuación y escenografía de una determinada representación teatral. Autores como el propio Ochoa o el conde de Campo Alange, escritores prolíficos en todos los ámbitos y secciones de la revista, dedicaron gran parte de sus publicaciones a la descripción y análisis de la escena teatral. Junto a ellos, Ventura de la Vega, José Bermúdez de Castro o José de Espronceda colaboraron, aunque de modo más tímido, en la elaboración de reseñas teatrales. La abundancia de textos sobre esta temática contrasta fuertemente con la escasez de artículos sobre narrativa o poesía, géneros que apenas son tratados desde un punto de vista teórico.

Desde sus páginas, El Artista denunció de forma constante el desastroso estado en el que se encontraba el teatro español, preocupación que no solo afectó a los redactores de la revista, sino que fue común para todas las escuelas y tendencias. Quizá, y así se refleja en el estudio previo que precede a la publicación madrileña ${ }^{2}$, los románticos otorgaron mayor gravedad a la decadencia del teatro porque lo consideraban el género propicio para combatir, como ya había ocurrido en Francia, a los defensores del clasicismo. El exceso de traducciones, causa indudable de la crisis teatral, se convirtió en el principal objeto de crítica; muchos autores atacaron lo que consideraban el mayor obstáculo para el florecimiento de un teatro nacional que, por entonces, se mostraba demasiado apegado a las piezas extranjeras. «La manía de las traducciones ha llegado ya a su colmo. Nuestra nación, en otros tiempos tan original, no

1. Veáse Ayala Aracil (2002).

2. Estudio preliminar de Ángel González García y Francisco Calvo Serraller en el facsímile de El Artista (1993). 
es otra cosa en el día que una nación traducida» (Mesonero Romanos cit. por Dengler Gassin 1989, p. 307). Mesonero Romanos denunciaba en estos términos el exceso de obras foráneas que llegaban a territorio nacional mediante las traducciones. En efecto, las creaciones propias y originales eran un bien que escaseaba en el panorama teatral decimonónico; una ojeada a la cartelera madrileña refleja que, entre 1830 y 1850, las obras extranjeras - la mayoría de origen francés- que habían sido representadas en los dos teatros de la capital suponían un $60 \%$ de la producción total. Ante este dato tan alarmante, es lógico pensar que los dramaturgos, críticos teatrales y demás individuos ligados a este género intentaran reducir el exceso de traducciones que, como si de una plaga se tratara, se había extendido por el mundo del teatro. Así se entiende que Eugenio de Ochoa reaccionara ante declararaciones que, como la que sigue, apoyan la traducción: «Pero si las obras originales han de ser como el Maniquí, vengan traducciones, que por malas que sean serán más tolerables y no influirán tan directamente en el descrédito de nuestra literatura $»^{3}$ (II, p.39). Estas palabras proceden de Biblioteca Universal de todos los conocimientos humanos, obra de carácter didáctico que el editor madrileño elogia en uno de los artículos de El Artista; sin embargo, lo que empieza siendo crítica de esta obra, recientemente publicada, se torna análisis del estado del teatro y, por consiguiente, alegato en favor de la creación de obras originales; un giro que no sorprende en El Artista, tan predispuesto siempre a abordar los grandes asuntos teatrales. Como respuesta, Eugenio de Ochoa proporciona una serie de razones que ponen de relieve el efecto perjudicial de las tan criticadas traducciones. Oponiéndose al criterio de los redactores de la Biblioteca Universal, considera que el auténtico descrédito de la literatura nacional no procede de las obras originales, sino de las traducidas, cuya excesiva demanda impide el desarrollo de «nuestros ingenios». Por ello, es imprescindible y urgente estimular las producciones de carácter nacional, verdadero componente de la literatura española, aunque ello conlleve, en algunos casos, la elaboración de dramas como el Maniquí, considerada no solo por los editores de la Biblioteca Universal, sino también por los de El Artista, una obra de escaso interés. Obra que, a pesar de su pésima calidad o justamente por ella, es necesaria para la creación de las grandes piezas teatrales:

¿Ignora este escritor que solo a fuerza de estímulos, de ensayos, de triunfos, de derrotas puede llegar a establecerse entre los jóvenes autores la emulación

3. Tomo la cita de El Artista (Madrid. 1835-1836), facsímile con estudio preliminar de Ángel González García y Francisco Clavo Serraller, Madrid, Turner, 3 volúmenes, 1981. En adelante indico volumen y páginas a continuación de la cita. 
necesaria de las cosas? ¿No se acuerda de aquel refrán tan conocido; quién no se embarca no pasa la mar? (II, p.39)

Este principio, desconocido e ignorado en territorio español, es, por lo que apunta el joven editor, de práctica común en Francia, donde anteponen a la grandeza de Shakespeare o de Calderón las obras de carácter nacional, incluidas aquellas que, por sus despropósitos y desatinos, son recibidas con abucheos. El público español, por el contrario, se muestra más benévolo con las traducciones, a las que disculpa errores y fallos que reprueba con contundencia en las creaciones originales. El ingenio nacional, maltratado por un público que prefiere a toda costa la obra teatral extranjera, acaba, en muchos casos, apostando también por la traducción. Los espectadores, no obstante, no son el único sector que infravalora a los autores españoles; los propios críticos teatrales enjuician a estos escritores con una dureza innecesaria. Por ello, Eugenio de Ochoa denuncia el trato que recibe el autor del Maniquí, el Sr. Andrew Covert-Spring. Los redactores de la Biblioteca Nacional, lejos de limitarse a valorar la pieza teatral, realizan un ataque personal hacia el propio escritor, del que se burlan por su «imaginación raquítica» e incluso por lo sonoro y estrambótico de su nombre. Estos reproches, que rozan la crueldad, dificultan, en opinión de Eugenio de Ochoa, el surgimiento de nuevos talentos nacionales, pues estos huyen del escarnio público al que se pueden ver sometidos si su obra no es del agrado de cierta crítica.

Quizá pueda resultar poco coherente descubrir que el editor de El Artista, defensor apasionado de las obras originales, contribuyera con traducciones a esta problemática que perjudicaba al teatro español. Dramas teatrales como Hernani o el honor castellano de Victor Hugo o Antoni de Alejandro Dumas, del que se publica un fragmento en el primer tomo de El Artista, pasaron a la escena española de la mano de Eugenio de Ochoa. Indudablemente, el joven escritor estaba interesado por las ideas que habían surgido en Francia y pretendía dar a conocer en territorio español el romanticismo exaltado que caracterizaba al francés Victor Hugo. Para ello, lógicamente, importó los dramas franceses que reproducían esta tendencia romántica. Las traducciones de Eugenio de Ochoa no buscaban reemplazar las obras originales, sino introducir un nuevo tipo de romanticismo que enriqueciera el teatro nacional. No obstante, las obras de Hugo o Dumas, que por su calidad merecían ser representadas en escenarios españoles, no suponían realmente ningún obstáculo para la creación de obras originales; eran los autores como Scribe, fecundos e incansables, quienes verdaderamente desesperaban a los editores de El Artista $\mathrm{y}$ al resto de defensores del teatro nacional. 
Las traducciones, sin embargo, no eran el único problema que afectaba al panorama teatral del momento. A la profusión de piezas extranjeras había que añadir además la presencia de la ópera, que gozó de gran popularidad entre el público, especialmente entre las clases altas. Larra en su artículo «Horas de invierno», publicado el 25 de diciembre de 1836 en El Español. Diario de las Doctrinas y los Intereses Sociales, refleja esta problemática: «¿Será el teatro el refugio de nuestra gloria? $i$ El teatro, sin actores y sin público, el teatro nacional, que por último insulto, para mengua eterna y degradación sin fin del país, es ya una sucursal de la ópera y un llena-huecos para las noches en que está ronca la primera dama?» (Larra, 1836). Eugenio de Ochoa se suma también a esta crítica de la ópera realizada por Fígaro y denuncia en el texto «Reflexiones sueltas» el derroche que supone su mantenimiento. Los motivos que el joven editor aduce para censurar este género son bien distintos de los que esgrimía para atacar las traducciones. Si las piezas extranjeras se adueñan de los escenarios, proporcionando apenas espacio para la producciones nacionales; la ópera acapara la mayoría de dinero destinado a los espectáculos. De acuerdo con el joven editor de El Artista, mientras otras naciones como la italiana, la francesa o la alemana pueden permitirse este lujo, España ha de renunciar a él en favor de su teatro. Salvo rarísimas excepciones, los grandes artistas que han otorgado fama y renombre a su país han desarrollado su talento gracias, en parte, a los estímulos económicos. Si se descuida la financiación del teatro, los buenos poetas dramáticos abandonarán la labor literaria, y los actores, desanimados ante la escasa valoración que reciben, desatenderán el estudio y la formación.

Este artículo apunta otro dato relevante para entender la situación decadente por la que pasa el teatro. Una vez más, Eugenio de Ochoa describe la ya famosa problemática de las traducciones; en esta ocasión, sin embargo, profundiza en el tema e intenta evidenciar los motivos que la expliquen. Es entonces cuando encuentra al verdadero culpable de la crisis teatral: el público. Aunque ya en otros artículos los redactores de El Artista habían criticado la apatía o el mal gusto que caracteriza a los aficionados, nunca antes lo habían señalado con dedo acusador. La culpabilidad del público exime de responsabilidades a la empresa de teatros, que debe mirar por su interés y apostar por obras que sean rentables. El público resulta, sin duda, una pieza clave en este entramado; de ahí que se aluda constantemente a sus reacciones en las representaciones teatrales. Sin embargo, su grado de responsabilidad en esta decadencia no está del todo clara. Si bien este texto acusa sin miramientos al espectador y lo considera el principal causante de la crisis; existen otros artículos en los que su apatía queda justificada. 
Con el objetivo de poner freno al deterioro que había invadido el panorama teatral del momento, los editores de El Artista apostaron por el nuevo y emergente movimiento romántico. El teatro del Siglo de Oro y, especialmente, los nuevos dramas románticos se convirtieron en material recurrente de la publicación madrileña, publicación que no se limitó a difundir y consolidar el romanticismo histórico, sino que apostó por una batalla todavía más difícil como era la aclimatación del romanticismo exaltado, vertiente que se personificaba en los franceses Victor Hugo y Alejandro Dumas. ${ }^{4}$. Estas dos concepciones teatrales, aunque defendidas ambas por los editores de la revista, tienen una presencia desigual en las páginas de la publicación madrileña. Dicha disparidad no es casual, sino fruto de una serie de circunstancias de carácter literario. Por un lado, el romanticismo español halla en 1835 - fecha en la que surge El Artista - un año crucial para su desarrollo teatral. Ya en 1834, habían aparecido obras teatrales, como La conjuración de Venecia de Martínez de la Rosa $^{5}$ o Macías de Larra, que iniciaban el despertar de una nueva sensibilidad. Sin embargo, habrá que esperar un año más para que las obras de los grandes apóstoles del romanticismo alcancen el escenario español. Como no podía ser de otro modo, El Artista aborda en sus páginas estos estrenos teatrales que constituyen un verdadero hito en la consolidación del teatro romántico. Por otro lado, los nuevos dramas despertaban rechazo entre el público y parte de la crítica; lo que obligó a los redactores de El Artista a realizar una campaña a su favor a través de la revista madrileña.

Esta disparidad es más acusada en los textos dedicados a la crítica literaria, donde el teatro del Siglo de Oro solo cuenta realmente con dos artículos. Su presencia, sin embargo, es mayor en otro tipo de escritos como las biografías, donde los redactores de la revista pueden alabar a las grandes figuras literarias de este período. Mientras el nuevo teatro romántico precisa de artículos polémicos que analicen sus virtudes y defectos, así como sus innovaciones; el teatro del Siglo de Oro es más propicio a textos moderados que reemplazan la controversia por el simple y llano elogio.

Mayor protagonismo, sin duda, tuvo el nuevo drama romántico. Los editores de El Artista, movidos por su deseo de difundir esta tendencia teatral,

4. Veáse Alonso Seoane (2002). Dice: «La batalla es tan violenta, al menos interna o soterradamente, porque estos jóvenes, a pesar de sus intentos de equilibrio, lo que proponen es precisamente un romanticismo más actual que el histórico; y, en el terreno del canon, abrirlo a los autores recientes. Es decir, proponen la apertura del canon romántico ya consolidado, para formar un canon romántico nuevo, difícil todavía de reconocer en España por su modernidad».

5. Veáse Ferri Coll (2010). 
le dedicaron diversos artículos de carácter teórico y práctico. Aunque poco inclinados a la traducción de obras extranjeras, los redactores recibieron con agrado las obras francesas de Victor Hugo y Dumas, piezas teatrales que el panorama literario precisaba con rapidez. Este es, al menos, el mensaje que se desprende de un comunicado emitido con motivo de la representación de Lucrecia Borgia. El Artista, que comparte las ideas allí expresadas, reproduce este texto procedente de la empresa de teatros. En él se justifica la elección de esta obra de Victor Hugo, con la que se pretende reformar la escena teatral. Atendiendo a este comunicado, las piezas de los célebres autores del siglo XVII han perdido prestigio y ni siquiera el intento por reanimarlas a través de refundiciones ha surtido efecto; la comedia neoclásica moratiniana ya no llena teatros y el drama sentimental aburre al público. Ante este deterioro del teatro, «es ya forzosa una verdadera revolución literaria, y en materia de espectáculos teatrales nada puede convenir tanto al severo carácter de las ideas modernas, como el drama grave, profundo, filosófico, a cuya cabeza brillan Victor Hugo y Alejandro Dumas» (II, p.34). Esta misma idea es la que desarrolla Eugenio de Ochoa al reseñar, una vez estrenada y representada, la pieza teatral Lucrecia Borgia. El joven editor, que no escatima en elogios, dedica alabanzas al talentoso Victor Hugo, considerado junto a Alejandro Dumas, el coloso del teatro moderno francés. El propio drama, así como el género que representa, también reciben un juicio favorable: Lucrecia Borgia, «creación tan gigantesca como el genio de Victor Hugo», está destinada no solo a convertirse en una obra relevante, sino a reformular los postulados del teatro. Su estreno es, tan solo, el inicio de un camino que recorrerán otras grandes creaciones dramáticas.

Este optimismo, sin embargo, es ligeramente ensombrecido por la cuestionable acogida que la obra tiene entre el público. En esta reseña ya se intuye, por tanto, la problemática que gira en torno a estos dramas románticos. La mayoría de ellos, tachados de indecentes e inmorales, tendrán que luchar contra un aluvión de críticas. En este caso, sin embargo, la actitud del público no es tanto de censura o reproche como de confusión, «Lucrecia Borja ha aterrado a nuestro público, le ha cogido de improviso y por fuerza le ha arrancado aplausos» (II, p.47). Los espectadores, sorprendidos ante el rumbo que adopta el teatro, no logran apreciar la belleza de estas obras, intuyen en ellas innovaciones y virtudes, pero no alcanzan a comprenderlas y, menos aún, a disfrutarlas: «este drama, lo repetimos, ha aterrado, ha conmovido hasta el fondo de sus entrañas a los espectadores españoles, ha ejercido sobre ellos el influjo de un talismán, pero decir que les ha gustado sería inexacto» (II, p.47). $\mathrm{Su}$ falta de costumbre ante estos dramas y su escasa educación teatral son los 
obstáculos que el público debe vencer para poder entender y estimar las nuevas tendencias dramáticas.

El texto que Eugenio de Ochoa escribe acerca de Angelo, el segundo drama de Victor Hugo representado en España, recoge las mismas ideas que ya se han expuesto con anterioridad: el editor vuelve a hacer referencia a la importancia de estos nuevos dramas que han de imprimir a la sociedad y, concretamente, al mundo literario un nuevo rumbo. Insiste, además, en la dificultad que la mayoría del público tendrá para acceder a estas obras. Solo el lector familiarizado con el lenguaje y el estilo de Victor Hugo penetrará su verdadero significado. Como no podía ser de otro modo, el escritor romántico es nuevamente elogiado. En este caso se ensalza su capacidad para dirigirise al hombre. Sus obras trascienden las circunstancias políticas y sociales y alcanzan verdaderamente al individuo. Solo grandes autores como Calderón, Shakespeare y, por supuesto, el gran poeta romántico Victor Hugo logran hablar a la humanidad:

Entusiasmarán las obras dramáticas de Voltaire mientres queden vestigios del partido a quien hablaba aquel gran hombre; las de Moliere, mientras sea la sociedad lo que era en tiempo de Luis XIV; las de Calderón, Shakespeare y Víctor Hugo mientras haya hombres en el mundo, porque lo repetimos, el primero hablaba a un partido, el segundo a la sociedad y los otros tres al hombre. (II, p. 108)

En esta ocasión, sin embargo, ya no se alude a un público sorprendido que reacciona tímidamente. Los espectadores, que en la reseña de Lucrecia Borgia no habían apreciado en su totalidad el nuevo drama romántico, reciben a Angelo con aplausos: «Pero en efecto, ¿qué pudiéramos decir de él? ¿Que ha sido muy aplaudido en Madrid? Nadie lo ignora» (II, p.108).

Para cualquier lector neófito en el tema, estas declararaciones podrían dar una imagen errónea de los nuevos dramas románticos. La visión de aceptación e incluso de aprobación hacia estas obras francesas, que Eugenio de Ochoa retrata con entusiasmo, no refleja con exactitud la realidad del momento. Como ya se ha adelantado, estas innovadoras piezas teatrales desarrollan un romanticismo exaltado y, hasta cierto punto, radical que no casaba con gran parte de la sociedad. Entre las reacciones negativas de la crítica cabe destacar la de El Eco del Comercio, a la que alude El Artista en su texto «Del drama moderno en Francia». En él, los redactores de este periódico madrileño acusan al moderno teatro francés de desarrollar un gusto excesivo por temas truculentos como el asesinato, el incesto o la violencia. Para apoyar su argumentación, proporcionan una estadística que refleja el alto número de crímenes que albergan estas obras, estadística que, por otro lado, resulta ridícula a ojos de los 
redactores de El Artista. El conde de Campo Alange, autor del ya mencionado «Del drama moderno en Francia», intenta desmentir el duro juicio emitido contra estas obras francesas. Él mismo se muestra crítico con los excesos y monstruosidades que presentan ciertas obras teatrales «que a ningún género pertenecen, y que, tal vez con demasiada frecuencia, se representan en algunos teatros de Francia» (I, p. 95). Pero este no es el caso de las piezas teatrales de Dumas o Victor Hugo, cuyos argumentos no exceden la crueldad de ciertas tragedias griegas.

Los estrenos franceses no fueron, sin embargo, los únicos que padecieron este tipo de comentarios. Los dramas españoles que se inscribieron a la nueva escuela recibieron un trato análogo. Así, El Artista elogió, como ya había hecho con los dramas franceses, estas piezas nacionales. Pero, como sucediera con las obras de Victor Hugo y Dumas, los nuevos dramas españoles también tuvieron que lidiar con las críticas. De nuevo, El Eco del Comercio censuró los principios de la escuela romántica y acusó, esta vez, a Don Álvaro o la fuerza del sino de recrearse innecesariamente en el horror. El conde de Campo Alange, en su reseña de este drama romántico, esgrimió el mismo argumento que había empleado con anterioridad para defender la obra de Victor Hugo, a saber, la comparación con el teatro griego.

A pesar de la tenaz campaña que El Artista llevó a cabo para defender el nuevo drama romántico, algunos de sus colaboradores se mostraron críticos con ciertos aspectos. Así, Eugenio de Ochoa, en su traducción de Antony, introdujo una serie de cambios que mitigaban la violencia y las blasfemias del original. Más curioso es el tratamiento que dispensan a la obra Angelo. En la entrega X del segundo tomo, aparece en el apartado «Variedades» una pequeña nota que se refiere en estos términos a la obra de Victor Hugo: «Nos extasiamos en la contemplación de las altas bellezas dramáticas en que abunda la última producción de Victor Hugo, el Angelo, Tirano de Padua» (II, p.119). Más adelante añade: «Favorable ocasión es esta para recordar que El Artista se abstuvo prudentemente de dar su opinión acerca del Angelo en particular, contentándose con hablar del carácter peculiar de los dramas en general del gran poeta Victor Hugo» (II, p. 119). Ciertamente, la reseña teatral que la revista romántica realiza con motivo del Angelo elude cualquier análisis o comentario concreto sobre la obra. Este silencio con el que prudentemente tratan la pieza teatral pronto da paso a una crítica abierta y explítica. En la entrega XV de este mismo tomo, Eugenio de Ochoa dedica estas palabras a Angelo: "Que este drama es malo, destestable, es fácil demostrarlo (y hay pocos de que pueda decirse otro tanto) matemáticamente, y no apoyándose en códigos sujetos al capricho de esta o la otra escuela, sino en las reglas eternas 
de la razón y de la moral» (II, p.116). Muy posiblemente esta declaración constituya los primeros pasos de un proceso que, finalmente, desembocó en el arrepentimiento de la labor romántica ${ }^{6}$. La defensa a ultranza del romanticismo francés que Eugenio de Ochoa llevó a cabo durante su apasionada juventud derivó en una actitud más moderada. Una vez muerta esta inclinación juvenil, manifestó ciertos remordimientos por haber traducido las novelas de George Sand y la obra Antoni de Dumas. De hecho, años más tarde, el que fuera editor de la revista romántica El Artista se opuso al reestreno de esta obra.

$\mathrm{Al}$ apostar por un teatro de claro sabor romántico, los editores de El Artista se oponían necesariamente a los defensores de la vieja escuela, rebautizados con el nombre de clasiquistas. Estos consideraban que las reglas del buen gusto sobre las que se debía asentar cualquier obra de calidad ya estaban fijadas por autores como «Aristóteles, Horacio, Boileau, Mengs y Palomino» (I, p.86); por lo que cualquier cambio que se alejara de dichos preceptos resultaba innecesario y perjudicial. Este desdén por las innovaciones - reflejo de una desconfianza en la capacidad artística del siglo XIX - sumerge en la rutina a la literatura, que debe repetir de modo ineludible las pautas creadas por los clásicos. Los románticos, por el contrario, rechazaban esta visión inmovilista del arte y creían en su continua evolución. Para ellos, la literatura debía ser fruto y expresión de su tiempo.

Esta batalla entre románticos y clasiquistas tuvo especial importancia en el ámbito del teatro, donde el debate acerca de las unidades clásicas fue un punto crucial. Como era de esperar, los románticos se opusieron a un seguimiento estricto de estas reglas, a las que consideraban un yugo. Las razones aportadas para justificar esta decisión se encuentran en numerosos artículos de El Artista. En «Teatro», por ejemplo, el conde de Campo Alange rechaza estas pautas porque ahogan el genio hasta hacerlo desaparecer. Si bien el uso de estas normas proporciona una obra correcta, elimina al mismo tiempo cualquier nota de talento o brillo. Por tanto, el producto artístico que surge del cumplimiento riguroso de las unidades es adecuado pero insulso. Así lo explica el propio José Negrete, conde de Campo Alange:

Ha formado un código, clasificando los delitos en que puede incurrir un escritor, y dando fórmulas para producir obras de formas sumamente regulares, sin ninguna monstruosidad, tersas y apacibles como el agua de una laguna, aunque sean como ella sin transparencia, insípidas y prosaicas. (I, p. 54)

Luis de Usoz y Río en su reseña sobre Talía Española aborda este mismo tema pero con una postura distinta. Sus armas para atacar las reglas aristótelicas

6. Veáse Randolph (1966).

Anales, 25, 2013, pp. 383-395 
no son las mismas que emplea su compañero, el conde de Campo Alange. La estrategia para censurar estas normas ya no radica en demostrar su efecto perjudicial, es decir, la supresión del genio o talento; sino en cuestionar su origen. Las famosas unidades son defendidas por su procedencia aristotélica; sin embargo, Luis de Usoz y Río matiza esta cuestión, demostrando que los clasiquistas han interpretado erróneamente las palabras del gran filósofo:

La unidad de lugar, y la, así llamada unidad de tiempo, no son reglas fundadas en la razón del arte, ni emanadas de la índole del poema dramático, sino que se originan de una autoridad no bien entendida y de arbitrarios principios, lo que aparece claro a quien observe el origen de dichas unidades. La unidad de lugar ha nacido del hecho que la mayor parte de las tragedias griegas imitan una acción que se ejecuta en un solo lugar, y de la idea que se tiene de que el teatro griego ha de ser el perpetuo y exclusivo modelo de la perfección dramática. La unidad de tiempo tuvo origen en un paso de Aristóteles, que, como observa Schlegel, no contiene un precepto, sino la simple relación de un hecho: esto es de la práctica más general del teatro griego. (I, p.34)

Según se colige de estas palabras, los defensores del clasicismo han adoptado como principios rígidos lo que tan solo era descripción de la realidad. Para Luis de Usoz y Río, la pretensión de Aristóteles no era establecer un canon del arte, sino detallar los rasgos del teatro de su tiempo. El colaborador de El Artista continúa su argumentación refutando uno de los defectos que se le atribuye a la literatura romántica: la inverosimilitud. Según los partidarios del clasicismo, la violación de las unidades de tiempo y lugar conduce necesariamente a este error. Una obra que transcurre en diferentes lugares y durante un período de tiempo considerado se torna inverosímil para el espectador, que sabe perfectamente que no se ha movido de su silla y que la representación no ha supuesto más de unas horas. Esta deficiencia que se le achaca a las diferentes obras románticas, entre ellas a Don Álvaro o la fuerza del sino, es desmentida por Luis de Usoz y Río, quien afirma que el espectador no forma parte del drama, sino que es «una mente extrínseca que la contempla».

A pesar de estas afirmaciones, los románticos no se oponen totalmente a las unidades de tiempo y lugar, sino que apuestan por un uso moderado y coherente de las reglas. Así, el conde de Campo Alange critica las actitudes extremas de ambas escuelas; para él merecen el mismo rechazo los que cumplen escrupulosamente estas normas, como los que las ignoran y las desobedecen constantemente. En la segunda parte de su artículo «Teatro», ilustra a la perfección el uso que ambas escuelas hacen de los principios clásicos: «Los otros ven en las reglas una indicación de los límites que conviene no traspasar, mas no una prescripción del camino que se ha de seguir» (I, p. 68). Así, mientras los seguidores del clasicismo no se apartan de estas reglas, aunque ello vaya 
en detrimento de la obra; los románticos se despojan de este yugo y solo ven en las normas un referente que les sirva de orientación. En este mismo texto, el conde de Campo Alange defiende el drama moderno de las acusaciones proferidas por los clasicistas. Al tratarse de un género mixto que las antiguas poéticas no incluyen, los defensores de la vieja escuela lo han considerado una degradación del arte. En su defensa, el conde de Campo Alange esgrime varios y diversos argumentos que impugnan los reproches que ha recibido este género. Para justificar su carácter mixto, se vale de la propia realidad, donde lo dulce y lo amargo se dan de forma mezclada:

Ya hemos dicho que en la naturaleza va mezclado lo sublime con lo trivial, lo horrible con lo halagüeño, y sobre todo, que así como en la pintura la oposición de los colores no hace sino aumentar respectivamente la fuerza y brillo de cada uno; del mismo modo el constraste de una escena amable o jocosa con otra terrible (siempre que no haya exageración), produce una impresión mil veces más profunda que la que de esta última escena aislada resultaría. (I, p. 70)

Para apoyar su causa, el conde de Campo Alange acude a Laharpe -crítico severo y de marcado gusto clásico-, quien reconoce que el carácter mixto así como el resto de defectos que posee el drama son superados por su gran capacidad para despertar interés.

A pesar de esta controversia que enfrentó a románticos y clasiquistas, Eugenio de Ochoa se mostró tolerante con esta tendencia literaria y dedicó parte de sus páginas a la publicación de algunas obras de tinte neoclásico. Así, Lista, que fue maestro del joven Ochoa, participó, aunque de manera breve, en la revista madrileña. Allen Randolph (Randolph 1966) ve en estas colaboraciones una negativa por parte de los autores románticos a romper definitivamente con sus antiguos preceptores. O quizá El Artista, siguiendo sus propios principios - expresados a lo largo de la revista — diera cabida a todos los textos de calidad, fuera cual fuera su inclinación o tendencia literaria.

\section{Bibliografía}

Alonso Seonne, Ma José, «La defensa del presente en El Artista y el nuevo canon romántico», en La elaboración del canon en la literatura española del siglo XIX, Luis F. Díaz Larios et al (eds.), Barcelona, Universidad, 2002, pp. 11-26.

El Artista. (Madrid. 1835-1836). facsímile con estudio preliminar de Ángel González García y Francisco Clavo Serraller, Madrid, Turner, 3 volúmenes, 1981.

Ayala ARACIL. $\mathrm{M}^{a}$ de los Ángeles, «La defensa de lo romántico en la revista literaria El Artista», en Los románticos teorizan sobre sí mismos, Bolonia, Il capitello del Sole, 2002, pp. 35-46. 
DENGLER GASSIN, Roberto, «El drama romántico francés en Madrid», en Imágenes de Francia en las letras hispánicas, Francisco Lafarga (ed.), Barcelona, Promociones y Publicaciones Universitarias, 1989, pp. 307-315.

Espín Templado. $\mathrm{M}^{\mathrm{a}}$ Pilar, «La teoría sobre las unidades de espacio y tiempo en la representación del drama romántico», en Los románticos teorizan sobre sí mismos, Bolonia, Il capitello del Sole, 2002, pp. 113-120.

FERri Coll, José María, «Los dramas históricos de Martínez de la Rosa. Memoria de un gran éxito», en Desde la Platea. Estudios sobre el teatro decimonónico, Editorial PUbliCAN, 2010, pp.22-33.

FERRI COLL, José María, «Las ilustraciones de El Artista y la idea de lo romántico en la década de 1830», en Literatura ilustrada decimonónica. 57 perspectivas, ed. Borja Rodríguez Gutiérrez y Raquel Gutiérrez Sebastián, Santander, Universidad de Cantabria, 2011, pp. 243-248.

Ferri Coll, José María, «El Artista y la ideación romántica de los géneros literarios», en Arbor; ciencia, pensamiento y cultura, n 712, CSIC, 2012, pp. 959-964.

LARRA, Mariano José de, «Horas de invierno», El Español. Diario de las Doctrinas y los Intereses Sociales, n. ${ }^{\circ} 420$, domingo 25 de diciembre de 1836, Madrid.

LÓPEZ SANZ, Genoveva Elvira, «Romanticismo frente a clasicismo en El Artista», Espéculo. Revista de estudios literarios, 2000, Ed. on line.

RANDOLPH, Donald Allen, Eugenio de Ochoa y el Romanticismo español, Berkeley y Los Angeles, University of California Press, 1966.

SHAW Donald L., «El drama romántico como modelo literario e ideológico», en Historia de la literatura española. Siglo XIX (I). Director de la obra: Víctor García de la Concha. Coordinador del volumen: Guillermo Carnero. Madrid, Espasa Calpe, 1997.

Fecha de recepción: 06/09/2013

Fecha de aceptación: 14/10/2013

Anales, 25, 2013, pp. 383-395 